\title{
Determination of carbohydrate composition in lignocellulosic biomass for biofuel production
}

\author{
Yengkhom Disco Singh a \\ a Department of Botany, School of Applied Sciences, \\ Centurion University of Technology and Management, Jatni, Bhubaneswar, India 752050

\section{Corresponding at: Yengkhom Disco Singh} \\ Email: disco.iitg@gmail.com
}

\begin{abstract}
Carbohydrate composition of lignocellulosic biomass is one of the main factors for production of biofuel from the plant biomass. Various methods like Thermogravimetric analysis (TGA), near infrared spectroscopy (NIR) often used in determination of polysaccharide component of the plant biomass. However, used of such tools is based on the prediction and very costly. This paper discussed about the determination of carbohydrate composition (cellulose, hemicellulose and lignin) using the automatic fibre estimation system. The protocol was developed for the estimation of cellulose, hemicellulose and lignin component of lignocellulosic biomass. This protocol explains a simple method to estimate the polysaccharide component of lignocellulosic biomass. This protocol can be used not only lignocellulosic biomass but also for other hardwood biomass. The advantages and techniques, procedures are presented below.
\end{abstract}

\section{Keywords: Lignocellulosic biomass; cellulose; hemicellulose; lignin; biofuel}

\section{Method details}

The estimation of composition of lignocellulosic biomass as feedstock for biofuel production is a crucial step in order to determine the efficiency of overall biochemical conversion to bioethanol $[4,5]$. Various standards methods such as gravimetric analysis, spectroscopic analysis, and chromatography have been routinely explored in the scientific literature. However, every protocol comes across some pros and cons. This paper details about the fiber estimation system through which the neutral detergent fiber (NDF), acid detergent fibre (ADF) and acid detergent 
lignin (ADL) were estimated. Based on the formula $[1,3$,$] the carbohydrate fractions were$ estimated.

Crude fibre is the portion of biomass residues that is insoluble after successive boiling with dilute acid and alkali. The difference in weight of the residue before and after the ashing is the weight of the crude fibre [2].

\section{Materials}

- Lignocellulosic biomass powder of particle size $1 \mathrm{~mm}$.

- Fibra plus three place automatic fiber estimation system

- Desiccator

- Crucible

- Analytical Balance - capable of weighing $0.1 \mathrm{mg}$.

- Oven - capable of maintaining a temperature of $102 \pm 2{ }^{\circ} \mathrm{C}$.

- Acetone

- Note: This list does not include generic laboratory equipment, which are assumed to be available.

Neutral Detergent Solution-Added 30g Sodium dodecyl sulfate (USP), 18.61g Ethylenediaminetetraacetic disodium salt (dehydrate), 6.81g Sodium borate, 4.56g Sodium phosphate dibasic (anhydrous), and 10.0ml of 2-Ethoxy ethanol (ethylene glycol mono ethyl ether) in a beaker of $500 \mathrm{ml}$ of distilled water. The mixture was stirred using the beat and magnetic stirrer. The volume was make up upto $1 \mathrm{~L}$ by adding distilled water. The $\mathrm{pH}$ was adjusted at 6.9 to 7.1

\section{Precautions}

Acetone is highly flammable material. Handle carefully and avoid inhaling or contact with skin. Sodium lauryl sulfate will irritate the mucous membranes. A dust mask and gloves should be worn when handling this chemical.

\section{Procedure}

The following procedure is for neutral detergent fibre determination. 
1. Weighed and record the weight of each empty crucible and zero the balance.

2. $0.50 \mathrm{~g}$ to $1.0 \mathrm{~g}$ of powdered sample was taken in the crucible and recorded the weight.

3. Added $100 \mathrm{ml}$ Neutral detergent solution, $2 \mathrm{ml}$ Decahydronaphthalene and $0.5 \mathrm{gm}$ sodium sulphite.

4. Heat to boil and reflux for $1 \mathrm{hr}$.

5. Filtered the sample and washed repeatedly using hot water.

6. Washed with acetone so as to remove the unwanted residues.

7. Dry the crucible in hot air oven at $100{ }^{\circ} \mathrm{C}$ for $8 \mathrm{hr}$.

8. Ash the residues in a muffle furnace at $500{ }^{\circ} \mathrm{C}$ for $3 \mathrm{hr}$.

Cell wall constituents $=($ Wt of crucible + cell wall constituents $)-$ Wt of crucible X 100

\section{Wt of sample}

Cell contents $=100-$ cell wall constituents

\section{Estimation of Acid detergent fibre (ADF)}

Acid detergent solution- Acid detergent solution was made by taking $1 \mathrm{~N} \mathrm{H}_{2} \mathrm{SO}_{4}$ (49.04 gm), Cetyle trimethyl ammonium bromide (CTAB) $(20 \mathrm{gm})$ in $1 \mathrm{~L}$ of distilled water.

\section{Procedure}

1. Weight $1 \mathrm{gm}$ of Lignocellusic biomass in a crucible.

2. Added $100 \mathrm{ml}$ of acid detergent solution and $2 \mathrm{ml}$ of Decahydronapthalene

3. The mixture was heat to boil and reflux for $1 \mathrm{hr}$.

4. Filtered the sample and rinsed with hot water

5. The sample was washed with acetone and then n-Hexane

6. The crucible containing sample was dried in an oven at $100{ }^{0} \mathrm{C}$ for $8 \mathrm{hr}$.

Acid detergent fibre $=($ Wt of crucible + fibre $)-$ Wt of crucible X 100 


\section{Estimation for Acid detergent lignin (ADL)}

$72 \%$ of $\mathrm{H}_{2} \mathrm{SO}_{4}$ was made by dissolving $583 \mathrm{ml}$ of $\mathrm{H}_{2} \mathrm{SO}_{4}$ in $417 \mathrm{ml}$ of distilled water.

\section{Procedure}

1. Acid detergent fibre prepared was taken ( the sample kept in oven dry at $100{ }^{0} \mathrm{C}$ for $8 \mathrm{hr}$ can be used for ADF).

2. $72 \%$ of $\mathrm{H}_{2} \mathrm{SO}_{4}$ was added to the ADF.

3. Filtered the sample in three times for $3 \mathrm{hrs}$. After the filtration, washed the sample using hot water until any free acid is remained.

4. The sample was dried in an oven for $8 \mathrm{hr}$ at $100{ }^{\circ} \mathrm{C}$.

5. Kept the crucible in muffle furnace at $500{ }^{0} \mathrm{C}$ for $3 \mathrm{hr}$ for ashing.

Acid detergent lignin $(A D L)=(\mathrm{Wt}$ of crucible + lignin $)-(\mathrm{Wt}$ of crucible + ash $) \mathrm{X} 100$

\section{Wt of sample}

Hemicellulose $\%=$ NDF $\%-$ ADF $\%$

Cellulose $\%=(\mathrm{Y}-\mathrm{L} / \mathrm{W}) \mathrm{X} 100$

Lignin $\%=(\mathrm{L}-\mathrm{A} / \mathrm{W}) \mathrm{X} 100$

where, $\mathrm{Y}=$ weight of $\mathrm{ADF}+$ crucible, $\mathrm{L}=$ weight of crucible + lignin, $\mathrm{A}=$ weight of crucible + ash, $\mathrm{W}=$ weight of sample. 


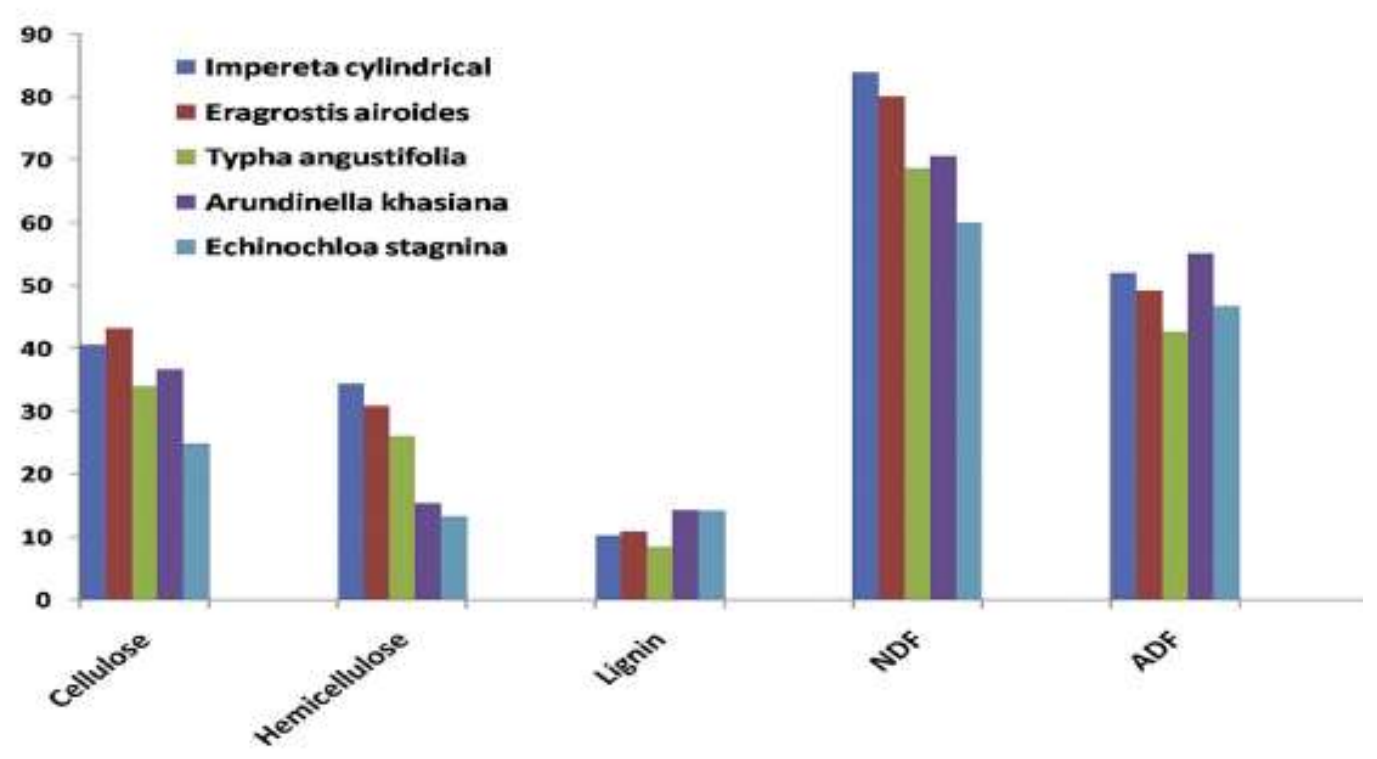

Fig. Compositional analysis of lignocellulosic biomass collected from Northeast India (adapted from $[6]$.

\section{Additional information}

Biomass is the most common form of renewable energy found abundantly throughout the world. The use of biomass as fuel has increased rapidly in last decade. Latterly, much attention has been focused on identifying suitable biomass species, which can provide high energy outputs, to replace conventional fossil fuel energy sources. The type of biomass used for the production of biofuel and its efficiency depends on the fuel criteria. As we know that, phytomass is produced by the green plant through the process called photosynthesis. Typically, photosynthesis converts less than $1 \%$ of the available sunlight energy to chemical energy and stored in the plant cells. The chemical energy stored is in the form of carbohydrate. When the bonds between adjacent carbon, hydrogen and oxygen molecules are decomposed, it released energy. If the biomass is processed efficiently, either chemically or biologically, by extracting the energy stored in the chemical bonds and the subsequent energy product combined with oxygen, the carbon is oxidised to produce $\mathrm{CO}_{2}$ and water. The process is cyclical, as the $\mathrm{CO}_{2}$ is then available to produce new biomass.

Numerous crops have been proposed for commercial energy farming by many countries. The potential energy crops mainly include woody crops, grasses, herbaceous plants, starch and sugar 
crops, oilseeds crops etc. However, due to the lack of technology in converting the biofuel in an efficient way, these crops need to come up with many new technologies to produce biomass in large-scale.

In general, the characteristics of ideal energy crops are:

- high yield (maximum production of dry matter per hectare),

- low energy input to produce, low cost,

- composition with the least contaminants,

- low nutrient requirements.

\section{Conflict of interest}

None declared

\section{Acknowledgements}

The author would like to thank IIT-Guwahati, Dr. Utpal Bora, center for energy for providing the facilities.

\section{Reference}

[1] P.J.Van Soest, J.B. Robertson, B.A. Lewis, Methods for dietary fiber, neutral detergent fiber and non-starch polysaccharides in relation to animal nutrition, J. Dairy Science. 74 (1991) 3583-3597.

[2] D. O. Holst, J. Assoc. Off. Anal. Chem. 65, 2 (1982) 265-269.

[3] M. Ioelovich, Methods for determination of chemical composition of plant biomass, Journal SITA. 17(4) (2015) 208-214.

[4] D. Hon, Chemical Modification of Lignocellulosic Materials. Marcel Dekker, New York, 1996

[5] M. Ioelovich, Plant Biomass as a Renewable Source of Biofuels and Biochemicals. LAP, Saarbrücken, 2013.

[6] Y.D. Singh et al., Comprehensive characterization of lignocellulosic biomass through proximate, ultimate and compositional analysis for bioenergy production, Renewable Energy 103 (2017) 490-500 